\title{
Interactions between serum urate- associated genetic variants and sex on gout risk: analysis of the UK Biobank
}

\author{
Ravi K. Narang ${ }^{1}$, Ruth Topless², Murray Cadzow², Greg Gamble ${ }^{1}$, Lisa K. Stamp ${ }^{3}$, Tony R. Merriman² and \\ Nicola Dalbeth ${ }^{1 *}$
}

\begin{abstract}
Background: Sex-specific differences in the effect of genetic variants on serum urate levels have been described. The aim of this study was to systematically examine whether serum urate-associated genetic variants differ in their influence on gout risk in men and women.

Methods: This research was conducted using the UK Biobank Resource. Thirty single nucleotide polymorphisms (SNPs) associated with serum urate were tested for their association with gout in men and women of European ancestry, aged 40-69 years. Gene-sex interactions for gout risk were analysed using an interaction analysis in logistic regression models.

Results: Gout was present in 6768 (4.1\%) men and 574 (0.3\%) women, with an odds ratio (95\% confidence interval) for men 13.42 (12.32-14.62) compared with women. In men, experiment-wide association with gout was observed for 21 of the 30 serum urate-associated SNPs tested, and in women for three of the 30 SNPs. Evidence for gene-sex interaction was observed for ABCG2 (rs2231142) and PDZK1 (rs1471633), with the interaction in ABCG2 driven by an amplified effect in men and in PDZK1 by an absence of effect in women. Similar findings were observed in a sensitivity analysis which excluded pre-menopausal women. For the other SNPs tested, no significant gene-sex interactions were observed.

Conclusions: In a large population of European ancestry, ABCG2 and PDZK1 gene-sex interactions exist for gout risk, with the serum urate-raising alleles exerting a greater influence on gout risk in men than in women. In contrast, other serum urate-associated genetic variants do not demonstrate significant gene-sex interactions for gout risk.
\end{abstract}

Keywords: Gout, Genetics, Urate

\section{Background}

Sex differences in the epidemiology, clinical characteristics, and risk factors for gout have been reported. Prevalence among gout is higher in men [1], and women with gout are more likely to be older, have co-morbidities, and be on diuretics compared with men with gout [2,3]. Similar findings have also been noted with respect to serum urate levels, with men having higher levels than women with these differences decreasing with advancing age [4].

\footnotetext{
* Correspondence: n.dalbeth@auckland.ac.nz

'Department of Medicine, Faculty of Medical and Health Sciences, University of Auckland, 85 Park Road, Grafton, Auckland 1023, New Zealand

Full list of author information is available at the end of the article
}

Raised serum urate is the major risk factor for gout [5, 6]. The heritability of serum urate is estimated at 40$70 \%$ [7-9] and over the past decade genome-wide association studies (GWAS) have identified single nucleotide polymorphisms (SNPs) associated with serum urate and gout [10-16]. Sex-specific analysis of genotypes associated with serum urate and gout have also been examined. The magnitude of effect of the ABCG2 variant appears to be greater in men than women for both serum urate and gout risk $[13,16]$. Conversely, the $S L C 2 A 9$ variant has been shown to exert greater influence for serum urate in pre-menopausal women compared with post-menopausal women and with men [17].

(c) The Author(s). 2019 Open Access This article is distributed under the terms of the Creative Commons Attribution 4.0 International License (http://creativecommons.org/licenses/by/4.0/), which permits unrestricted use, distribution, and 
It is unclear whether other serum urate-associated genetic variants display sex-specific differences for gout risk.

The aim of this study was to systematically examine whether serum urate-associated genetic variants differ in their influence on gout risk in men and women.

\section{Methods}

This research was conducted using the UK Biobank Resource (approval number 12611). Participants of European ancestry who were aged 40-69 years and with genome-wide genotypes were included in this study. Exclusion criteria included mismatch between self-reported sex and genetic sex, genotyping quality control failure, related individuals, and participants aged 70 years and over. Gout was defined using a validated definition of self-report of gout or urate-lowering therapy use (including allopurinol, febuxostat, and sulphinpyrazone, and participants must not have a hospital diagnosis of leukaemia or lymphoma based on the International Classification of Diseases, Tenth Revision codes C81-C96) [18]. For participants who did not meet the gout definition, further exclusion criteria included prescriptions for corticosteroids, non-steroidal anti-inflammatory drugs or probenecid. Medication use, co-morbidities, alcohol, smoking status, and menopausal status data were collected via self-report.

UK Biobank samples were genotyped using an Axiom array $(820,967$ markers, Affymetrix, Santa Clara, CA, USA) and imputed to approximately 73.3 million SNPs using SHAPEIT3 and IMPUTE2 with a combined UK10K and 1000 Genomes reference panel. We analysed the 30 SNPs associated with serum urate reported by Kottgen et al. [10] in the large (>140,000 European participants) Global Urate Genetics Consortium GWAS.

Data were analysed using IBM SPSS Statistics 25 software. Baseline characteristics are summarised using standard descriptive statistics including means, standard deviations (SD), and number and percent, and were tested using unpaired $t$ tests or chi-squared tests where appropriate. Logistic regression of the 30 SNPs with gout as the dependent variable in men and women was performed. The primary analysis calculated association with gout based on the proportion of participants with at least one effect allele present. The number of effect alleles was included in the secondary analysis. Gene-sex interactions for gout risk were analysed using logistic regression models that included an SNP by sex interaction term. Women with no effect allele were used as the referent group in the stratified logistic regression analysis. Age, body mass index, renal failure, and diuretic use were included as variables in all models. We also performed a sensitivity analysis which excluded pre-menopausal women.
Data are reported at experiment-wide significance $(P<0.0017)$.

\section{Results \\ Clinical features of participants}

Data including genome-wide genotypes were available for 359,876 participants. Baseline characteristics are shown in Table 1 with genotype frequencies of the 30 serum urate-associated SNPs shown in Additional file 1 (Table S1). There were 188,221 (53.2\%) women, of whom $142,272(75.6 \%)$ were post-menopausal. Overall, there were $7342(2.0 \%)$ participants fulfilling the study criteria for gout. Gout was present in 6768 (4.1\%) men and $574(0.3 \%)$ women, with an odds ratio (OR) of 13.42 (95\% confidence interval (CI) 12.32-14.62) for men compared with women. Women with gout were older (mean $\pm \mathrm{SD}, 61.8 \pm 5.9$ years vs $59.8 \pm$ 6.9 years, $\left.P=2.90 \times 10^{-11}\right)$, had a higher body mass index (BMI; $32.3 \pm 6.6 \mathrm{~kg} / \mathrm{m}^{2}$ vs $30.6 \pm 4.8 \mathrm{~kg} / \mathrm{m}^{2}, P$ $\left.=7.13 \times 10^{-16}\right)$, higher diuretic use $(35.9 \%$ vs $14.8 \%, P$ $\left.=6.05 \times 10^{-39}\right)$, and a higher prevalence of renal failure $\left(3.1 \%\right.$ vs $\left.1.3 \%, P=5.59 \times 10^{-4}\right)$ compared with men with gout.

\section{Association with gout of serum urate-associated SNPs in men and women}

In the entire group, association with gout at experimentwide significance was observed for 21 of the 30 serum urate-associated SNPs tested (Fig. 1). In men, experiment-wide association was observed for the same 21 SNPs, and in women this association was seen for three of the 30 SNPs: SLC2A9 (rs12498742), ABCG2 (rs2231142), and GCKR (rs1260326, Fig. 1).

Similar findings were observed when calculating allelic odds ratios based on the number of effect alleles present (Additional file 1: Tables S2 and S3). Association with gout at experiment-wide significance was observed for 22 SNPs in the entire group. In men, experiment-wide association was observed for the same 22 SNPs, and in women this association was seen for four of the 30 SNPs: SLC2A9 (rs12498742), ABCG2 (rs2231142), GCKR (rs1260326), and MLXIPL (rs1178977).

SLC2A9 (rs12498742) and ABCG2 (rs2231142) variants exerted the largest effect on gout risk in the group overall (OR for gout 3.07 (95\% CI 2.59-3.64), $P=8.30 \times$ $10^{-39}$ and $2.26(2.15-2.37), P=1.64 \times 10^{-233}$, respectively; Fig. 1). For the $A B C G 2$ variant a higher risk in men was observed compared with women (OR for gout in men 2.38 (95\% CI 2.26-2.51), $P=3.72 \times 10^{-235}$, and in women $\left.1.63(1.36-1.96), P=1.19 \times 10^{-7}\right)$, whilst for the $S L C 2 A 9$ variant the risk was not statistically different between sexes as demonstrated by overlapping 95\% CIs (OR for gout in men 3.06 (95\% CI 2.57-3.65), $P=6.71 \times$ 
Table 1 Baseline characteristics of participants according to overall group and sex

\begin{tabular}{|c|c|c|c|c|c|c|c|}
\hline & \multicolumn{2}{|l|}{$\begin{array}{l}\text { All patients } \\
n=359,876\end{array}$} & \multicolumn{2}{|l|}{$\begin{array}{l}\text { Women } \\
n=188,221\end{array}$} & \multicolumn{2}{|l|}{$\begin{array}{l}\text { Men } \\
n=171,655\end{array}$} & \multirow{2}{*}{$\begin{array}{l}\text { Men vs } \\
\text { women } \\
\text { (gout cases) } \\
P\end{array}$} \\
\hline & $\begin{array}{l}\text { Control } \\
n=352,534\end{array}$ & $\begin{array}{l}\text { Gout } \\
n=7342\end{array}$ & $\begin{array}{l}\text { Control } \\
n=187,647\end{array}$ & $\begin{array}{l}\text { Gout } \\
n=574\end{array}$ & $\begin{array}{l}\text { Control } \\
n=164,887\end{array}$ & $\begin{array}{l}\text { Gout } \\
n=6768\end{array}$ & \\
\hline Age, years (SD) & $56.9(8.0)$ & $60.0(6.9)$ & $56.8(7.9)$ & $61.8(5.9)$ & $57.0(8.1)$ & $59.8(6.9)$ & $2.90 \times 10^{-11}$ \\
\hline $\mathrm{BMI}, \mathrm{kg} / \mathrm{m}^{2}(\mathrm{SD})$ & $27.2(4.6)$ & $30.7(4.9)$ & $26.8(5.0)$ & $32.3(6.6)$ & $27.6(4.1)$ & $30.6(4.8)$ & $7.13 \times 10^{-16}$ \\
\hline Smoker, $n(\%)^{*}$ & $35,768(10.2 \%)$ & $661(9.0 \%)$ & $16,006(8.6 \%)$ & 59 (10.3\%) & $19,762(12.0 \%)$ & $602(8.9 \%)$ & 0.34 \\
\hline \multicolumn{8}{|l|}{ Alcohol frequency, $n(\%)^{*}$} \\
\hline Daily or almost daily & $74,318(21.1 \%)$ & 2475 (33.7\%) & $31,696(16.9 \%)$ & $90(15.7 \%)$ & $42,622(25.9 \%)$ & 2385 (35.3\%) & $8.12 \times 10^{-102}$ \\
\hline One to four times a week & $85,226(24.2 \%)$ & $2026(27.6 \%)$ & $40,499(21.6 \%)$ & $86(15.0 \%)$ & $44,727(27.1 \%)$ & $1940(28.7 \%)$ & \\
\hline Once or twice a week & 93,145 (26.4\%) & 1668 (22.7\%) & $49,718(26.5 \%)$ & $130(22.7 \%)$ & $43,427(26.4 \%)$ & 1538 (22.7\%) & \\
\hline Infrequent ${ }^{* *}$ & $76,172(21.6 \%)$ & $838(11.4 \%)$ & 50,509 (26.9\%) & $178(31.0 \%)$ & $25,663(15.5 \%)$ & $660(9.8 \%)$ & \\
\hline Never & $23,442(6.7 \%)$ & $327(4.5 \%)$ & $15,108(8.1 \%)$ & 89 (15.5\%) & $8334(5.1 \%)$ & $238(3.5 \%)$ & \\
\hline Diuretic use, $n(\%)^{*}$ & $28,722(8.1 \%)$ & $1210(16.5 \%)$ & $16,031(8.5 \%)$ & $206(35.9 \%)$ & $12,691(7.7 \%)$ & $1004(14.8 \%)$ & $6.05 \times 10^{-39}$ \\
\hline \multicolumn{8}{|l|}{ Co-morbidities, $n(\%)^{*}$} \\
\hline Hypercholesterolaemia & 42,929 (16.7\%) & $2056(28.2 \%)$ & $18,322(13.4 \%)$ & $180(31.6 \%)$ & 24,607 (20.5\%) & 1876 (27.9\%) & 0.06 \\
\hline Hypertension & 89,575 (34.9\%) & 4161 (57.0\%) & $42,152(30.8 \%)$ & $364(63.9 \%)$ & 47,423 (39.5\%) & 3797 (56.4\%) & $5.95 \times 10^{-4}$ \\
\hline Peripheral vascular disease & $616(0.2 \%)$ & $10(0.1 \%)$ & $358(0.3 \%)$ & $4(0.7 \%)$ & $258(0.2 \%)$ & $6(0.1 \%)$ & $1.47 \times 10^{-4}$ \\
\hline Angina & $11,265(4.4 \%)$ & $662(9.1 \%)$ & $3603(2.6 \%)$ & 59 (10.4\%) & $7662(6.4 \%)$ & $603(9.0 \%)$ & 0.27 \\
\hline Myocardial infarction & $8261(3.2 \%)$ & $521(7.1 \%)$ & $1604(1.2 \%)$ & $25(4.4 \%)$ & $6657(5.5 \%)$ & $496(7.4 \%)$ & 0.01 \\
\hline Heart failure & $196(0.1 \%)$ & $44(0.6 \%)$ & $73(0.1 \%)$ & $5(0.9 \%)$ & $123(0.1 \%)$ & $39(0.6 \%)$ & 0.38 \\
\hline Arrhythmia & $1952(0.8 \%)$ & $71(1.0 \%)$ & $950(0.7 \%)$ & $3(0.5 \%)$ & $1002(0.8 \%)$ & $68(1.0 \%)$ & 0.26 \\
\hline Stroke & $4733(1.8 \%)$ & $254(3.5 \%)$ & $1895(1.4 \%)$ & $31(5.4 \%)$ & $2838(2.4 \%)$ & $223(3.3 \%)$ & 0.01 \\
\hline Transient ischaemic attack & $1343(0.5 \%)$ & $59(0.8 \%)$ & $623(0.5 \%)$ & $5(0.9 \%)$ & $720(0.6 \%)$ & $54(0.8 \%)$ & 0.85 \\
\hline Renal failure & $443(0.1 \%)$ & $108(1.5 \%)$ & $222(0.1 \%)$ & $18(3.1 \%)$ & $221(0.1 \%)$ & $90(1.3 \%)$ & $5.59 \times 10^{-4}$ \\
\hline Diabetes mellitus & $16,108(6.3 \%)$ & 1005 (13.8\%) & 5846 (4.3\%) & $110(19.3 \%)$ & $10,262(8.5 \%)$ & 895 (13.3\%) & 0.01 \\
\hline
\end{tabular}

$B M I$ body mass index, $S D$ standard deviation

*Smoking status, alcohol frequency, medication use and co-morbidity data collected via self-report

** Infrequent alcohol frequency defined as one to three times a month, or special occasions only

$10^{-36}$, and in women $4.13(2.05-8.32), P=7.06 \times 10^{-5}$, Fig. 1).

\section{SNP-sex interaction analysis}

Evidence for gene-sex interaction was observed for ABCG2 (rs2231142) and PDZK1 (rs1471633), with the interaction at $A B C G 2$ driven by a larger effect in men, and at $P D Z K 1$ driven by an absence of effect in women (Fig. 2 and Table 2). For ABCG2, compared with women without the effect allele (referent group), the OR was 1.62 (95\% CI 1.35-1.94) in women with the effect allele, 11.99 (10.81-13.30) in men without the effect allele, and 28.65 (25.73-31.90) in men with the effect allele (interaction $P=4.59 \times 10^{-5}$ ). For $P D Z K 1$, compared with women without the effect allele (referent group), the OR was $0.92(95 \%$ CI $0.77-1.10)$ in women with the effect allele, $10.54(9.00-12.34)$ in men without the effect allele, and $13.61(11.68-15.85)$ in men with the effect allele (interaction $P=3.67 \times 10^{-4}$ ). For the other SNPs tested, no significant gene-sex interactions were observed (Table 2).

Similar findings were found in the sensitivity analysis when excluding pre-menopausal women (Additional file 1: Table S4 and Additional file 2: Figure S1). When analysing for gene-sex interaction according to the number of effect alleles present, interaction was also observed for $A B C G 2$ and $P D Z K 1$ in a similar pattern to that observed in the primary analysis (Fig. 3 and Additional file 1: Table S5).

\section{Discussion}

In this large population of European ancestry, we have identified gene-sex interactions for ABCG2 (rs2231142) and PDZK1 (rs1471633) for gout risk, with the serum urate-associated SNPs exerting a greater influence on gout risk in men than in women. Consistent with prior reports [1-3], women with gout were older, had a higher body mass index, higher diuretic use, and more renal failure compared with men with gout. Importantly, all 

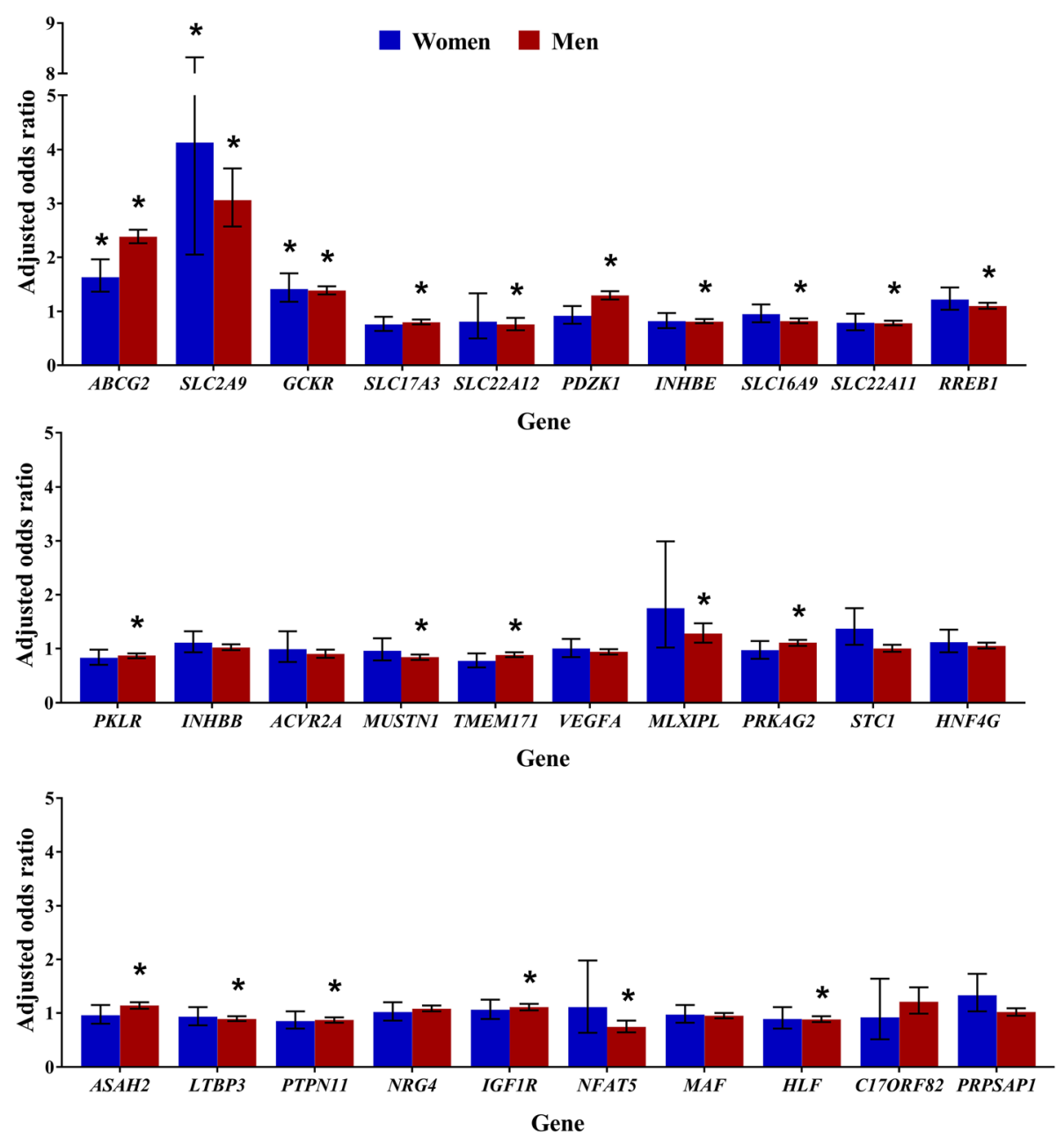

Fig. 1 Association analysis of 30 serum-urate associated single-nucleotide polymorphisms for gout. Data are adjusted for age, body mass index, diuretic use, and renal failure. *Experiment-wide significance at $P<0.0017$

analyses examining genetic associations included age, body mass index, diuretic use, and renal failure within the regression models.

Sex-specific differences for $A B C G 2$ variants on serum urate have been previously reported. A GWAS by Dehghan et al. [16] which included a total of 26,714 participants across the Framingham cohort study, the Rotterdam cohort study, and the Atherosclerosis Risk in Communities (ARIC) study demonstrated significant ABCG2 (rs2231142) gene-sex interactions for serum urate in participants of the Framingham study (of which almost all were of European descent) and for participants of European ancestry from the ARIC study. These differences were not observed in the Rotterdam cohort study or in African-American participants from the ARIC study. A 2009 meta-analysis by Kolz et al. [13] included 28,141 Europeans, and demonstrated that two $A B C G 2$ variants (rs2231142 and rs2199936) had significant effects on raising serum urate with the effect almost twice as strong in men compared with women. Differences for two PDZK1 variants (rs12129861 and rs147 1633) were also noted with urate-altering effects higher in men compared with women; however, the differences were not significant. Kottgen et al. [10] demonstrated similar differences in their large GWAS of $>140,000$ Europeans for the rs2231142 variant with a serum urate raising effect of $0.270 \mathrm{mg} / \mathrm{dl}$ in men vs $0.181 \mathrm{mg} / \mathrm{dl}$ in women.

For gout risk, sex-specific differences for $A B C G 2$ variants have also been described. The Population Architecture using Genomics and Epidemiology (PAGE) study, which examined the association between gout and the $A B C G 2$ rs2231142 SNP, found a higher risk for gout in men than women in a population which included 13,783 European Americans, 4271 African Americans, and 1373 Mexican Americans [19]. In the Dehghan et al. [16] meta-analysis, sex-specific differences for gout risk were also noted for participants of European ancestry from 

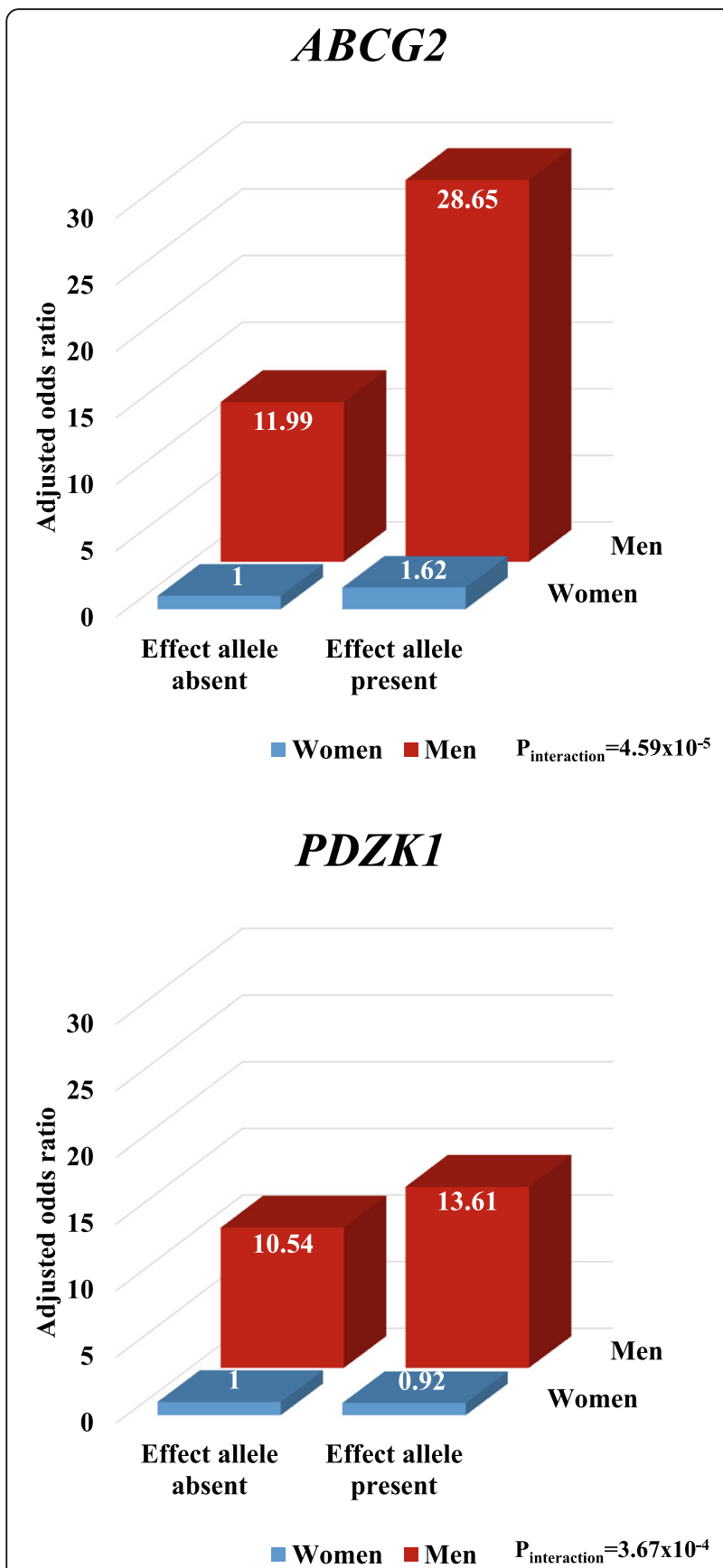

Fig. 2 Association and interaction between serum urate-associated genetic variants (for $A B C G 2$ and PDZK1) and sex for gout risk according to effect allele presence. Data are adjusted for age, body mass index, renal failure, and diuretic use. Experiment-wide significance is defined as $P<0.0017$

the ARIC cohort with the rs2231142 variant exerting a greater risk of gout in men compared with women (OR 2.03 (95\% CI 1.61-2.56) vs 1.07 (0.72-1.57), interaction $P=0.004)$. Contrasting results were found in a European and Eastern Polynesian population from New Zealand where gene-sex interactions for gout risk were not evident [20].

A causal mechanism for sex-specific differences with the $A B C G 2$ variant are unclear. There is strong evidence that oestrogen and progesterone reduce the risk of hyperuricaemia and development of gout due to their uricosuric effects [21-24]. Several studies in cell lines and animal models have shown that these hormones can regulate the activity of the ABCG2 transporter protein [25-28] and that these hormones may play a key role in ABCG2 transporter-mediated urate excretion at the level of the gut or kidney.

We are the first to report significant sex-specific differences for the PDZK1 variant (rs1471633) on gout risk. The PDZK1 protein is not directly involved in urate transport but has been shown to be a key regulatory scaffolding protein in tethering other urate transporters (e.g. ABCG2, SLC22A11, and SLC17A1) to the multimolecular transportasome complex, and there is evidence that this complex may be responsible for controlling urate regulation at the level of the proximal renal tubule [29-31]. Studies reporting the association of PDZK1 variants with gout have demonstrated mixed findings. Phipps-Green et al. [15] demonstrated an association between a $P D Z K 1$ variant (rs1967017) and gout in a New Zealand European and Polynesian sample set with the effect allele exerting an increased risk of gout (OR 1.12 (95\% CI 1.02-1.23)). The rs1967017 variant is the likely causal variant, with the urate-increasing allele causing increased PDZK1 expression [32]. An association between the rs12129861 variant and gout was also found in a Japanese population (OR 0.80 (95\% CI 0.67-0.96)) [33]. Similar findings have also been seen in a male Han Chinese population for both rs1967017 and rs12129861 PDKZ1 variants [34]; however, this was not replicated for rs12129861 in a larger case-control study involving Han Chinese individuals [35]. These contrasting results may be attributed to different study populations, sample sizes, or differences in the number of men and women in the sample sets.

For the other SNPs tested, gene-sex interactions were not identified. This includes SLC2A9 for which significant sex-specific differences for serum urate have been previously reported $[10,11,13,16]$. In our study, SLC2A9 had a large effect on gout risk in both men and women. However, we did not observe differential sex-specific differences for SLC2A9 on gout risk in the interaction analysis. This may be because a high proportion $(>90 \%)$ of participants in the analysis had at least one SLC2A9 effect allele and, in particular, there were very few women with gout who did not carry an effect allele $(n=8)$. This may have affected the power to detect sex-specific differences in gout risk for the SLC2A9 variant. However, our findings are consistent with Dehghan 
Table 2 Association and interaction between serum urate-associated single nucleotide polymorphisms and sex for gout risk

\begin{tabular}{|c|c|c|c|c|c|c|c|}
\hline \multirow[t]{2}{*}{ Gene } & \multirow[t]{2}{*}{ SNP } & \multirow[t]{2}{*}{$\begin{array}{l}\text { Effect } \\
\text { allele }\end{array}$} & \multicolumn{2}{|l|}{$\begin{array}{l}\text { Women } \\
n=188,221\end{array}$} & \multicolumn{2}{|l|}{$\begin{array}{l}\text { Men } \\
n=171,655\end{array}$} & \multirow{2}{*}{$\begin{array}{l}\text { Gene-sex } \\
\text { interaction } \\
P\end{array}$} \\
\hline & & & $\begin{array}{l}\text { Effect allele absent } \\
\text { Referent OR }\end{array}$ & $\begin{array}{l}\text { Effect allele present } \\
\text { OR }(95 \% \mathrm{Cl})\end{array}$ & $\begin{array}{l}\text { Effect allele absent } \\
\text { OR }(95 \% \mathrm{Cl})\end{array}$ & $\begin{array}{l}\text { Effect allele present } \\
\text { OR }(95 \% \mathrm{Cl})\end{array}$ & \\
\hline \multicolumn{8}{|c|}{ Loci replicated by Kottgen } \\
\hline$A B C G 2$ & rs2231142 & $\mathrm{T}$ & 1 & $1.62(1.35-1.94)$ & 11.99 (10.81-13.30) & 28.65 (25.73-31.90) & $4.59 \times 10^{-5}$ \\
\hline SLC2A9 & rs12498742 & A & 1 & $4.12(2.05-8.30)$ & $18.09(8.85-36.98)$ & $55.62(27.77-111.37)$ & 0.42 \\
\hline GCKR & rs1260326 & $\mathrm{T}$ & 1 & $1.42(1.18-1.70)$ & $13.80(11.77-16.18)$ & $19.08(16.33-22.29)$ & 0.80 \\
\hline SLC17A3 & rs1165151 & T & 1 & $0.76(0.64-0.91)$ & $13.15(11.38-15.20)$ & $10.56(9.16-12.17)$ & 0.60 \\
\hline SLC22A12 & rs478607 & A & 1 & $0.78(0.48-1.28)$ & $13.96(8.44-23.09)$ & $10.57(6.53-17.11)$ & 0.90 \\
\hline PDZK1 & rs1471633 & A & 1 & $0.92(0.77-1.10)$ & $10.54(9.00-12.34)$ & $13.61(11.68-15.85)$ & $3.67 \times 10^{-4}$ \\
\hline INHBE & rs3741414 & $\mathrm{T}$ & 1 & $0.82(0.69-0.98)$ & $13.57(12.16-15.15)$ & 11.06 (9.89-12.38) & 0.92 \\
\hline SLC16A9 & rs1171614 & $\mathrm{T}$ & 1 & $0.95(0.80-1.12)$ & $14.28(12.78-15.96)$ & $11.74(10.48-13.16)$ & 0.11 \\
\hline SLC22A11 & rs2078267 & $\mathrm{T}$ & 1 & $0.78(0.65-0.95)$ & $13.59(11.42-16.17)$ & $10.57(8.93-12.51)$ & 0.96 \\
\hline RREB1 & rs675209 & $\mathrm{T}$ & 1 & $1.23(1.04-1.45)$ & $14.28(12.62-16.16)$ & $15.74(13.90-17.82)$ & 0.23 \\
\hline \multicolumn{8}{|c|}{ Loci reported by Kottgen } \\
\hline$P K L R$ & rs11264341 & T & 1 & $0.82(0.69-0.97)$ & 13.09 (11.4-15.08) & 11.34 (9.87-13.02) & 0.57 \\
\hline INHBB & rs17050272 & A & 1 & $1.10(0.93-1.32)$ & $14.25(12.26-16.57)$ & $14.54(12.54-16.85)$ & 0.40 \\
\hline$A C V R 2 A$ & rs2307394 & $\mathrm{T}$ & 1 & $0.99(0.75-1.31)$ & $14.72(11.13-19.48)$ & $13.28(10.14-17.40)$ & 0.53 \\
\hline MUSTN1 & rs6770152 & $\mathrm{T}$ & 1 & $0.96(0.78-1.19)$ & $15.29(12.50-18.70)$ & $12.75(10.49-15.51)$ & 0.21 \\
\hline TMEM171 & rs17632159 & C & 1 & $0.76(0.65-0.90)$ & 12.81 (11.39-14.41) & $11.31(10.06-12.73)$ & 0.11 \\
\hline VEGFA & rs729761 & $\mathrm{T}$ & 1 & $0.99(0.84-1.17)$ & 13.89 (12.29-15.70) & $13.03(11.53-14.74)$ & 0.55 \\
\hline$M L X I P L$ & rs1178977 & A & 1 & $1.71(1.00-2.90)$ & $17.96(10.42-30.95)$ & $22.86(13.50-38.72)$ & 0.30 \\
\hline PRKAG2 & rs10480300 & T & 1 & $0.97(0.82-1.15)$ & $12.74(11.31-14.35)$ & $14.07(12.50-15.85)$ & 0.15 \\
\hline STC1 & rs17786744 & A & 1 & $1.36(1.06-1.74)$ & 17.59 (13.86-22.33) & 17.64 (13.99-22.25) & 0.02 \\
\hline HNF4G & rs2941484 & $\mathrm{T}$ & 1 & $1.11(0.92-1.33)$ & $14.00(11.89-16.49)$ & $14.78(12.59-17.34)$ & 0.62 \\
\hline ASAH2 & rs10821905 & A & 1 & $0.96(0.80-1.15)$ & $12.86(11.57-14.29)$ & $14.63(13.12-16.33)$ & 0.07 \\
\hline LTBP3 & rs642803 & T & 1 & $0.92(0.77-1.10)$ & $13.81(11.80-16.16)$ & $12.33(10.58-14.38)$ & 0.76 \\
\hline PTPN11 & rs653178 & T & 1 & $0.85(0.70-1.02)$ & $13.30(11.24-15.74)$ & $11.52(9.78-13.57)$ & 0.82 \\
\hline NRG4 & rs1394125 & A & 1 & $1.02(0.86-1.21)$ & $13.06(11.40-14.98)$ & $14.17(12.38-16.21)$ & 0.52 \\
\hline IGF1R & rs6598541 & A & 1 & $1.06(0.89-1.25)$ & 13.05 (11.38-14.96) & $14.48(12.65-16.56)$ & 0.59 \\
\hline NFAT5 & rs7193778 & $\mathrm{T}$ & 1 & $1.12(0.63-1.98)$ & $20.20(11.23-36.35)$ & $14.91(8.44-26.35)$ & 0.17 \\
\hline MAF & rs7188445 & A & 1 & $0.96(0.82-1.14)$ & $13.64(12.01-15.48)$ & $12.91(11.38-14.65)$ & 0.84 \\
\hline$H L F$ & rs7224610 & A & 1 & $0.90(0.72-1.12)$ & $13.76(11.13-17.00)$ & 12.13 (9.89-14.89) & 0.88 \\
\hline C17ORF82 & rs2079742 & T & 1 & $0.92(0.52-1.64)$ & $10.34(5.65-18.93)$ & $12.54(7.09-22.19)$ & 0.38 \\
\hline PRPSAP1 & rs164009 & $A$ & 1 & $1.32(1.02-1.71)$ & $17.00(13.25-21.82)$ & $17.27(13.55-22.01)$ & 0.05 \\
\hline
\end{tabular}

Association and interaction data are reported according to effect allele presence or absence

Data are adjusted by age, body mass index, diuretic use, and renal failure

Experiment-wide significance is defined as $P<0.0017$

$\mathrm{Cl}$ confidence interval, $\mathrm{OR}$ odds ratio, SNP single nucleotide polymorphism

et al. [16] who reported no evidence of a $S L C 2 A 9$ gene-sex interaction for gout risk despite reporting a significant differential sex-specific effect for serum urate.

Consistent with previous reports, SLC2A9 and ABCG2 variants exerted the highest risk for gout among the whole group $[10,15,16]$. Unlike these reports, our study shows that the SLC2A9 variant exerts a greater risk of gout compared with the $A B C G 2$ variant. When calculating gout risk based on allelic odds ratios, however, this increased risk between the two variants is reversed with the $A B C G 2$ variant demonstrating an increased risk of gout compared with SLC2A9 (Additional file 1: Table S2).

We acknowledge the limitations of this study. Firstly, our analysis was restricted to participants of European ancestry and our results may not be generalizable to 


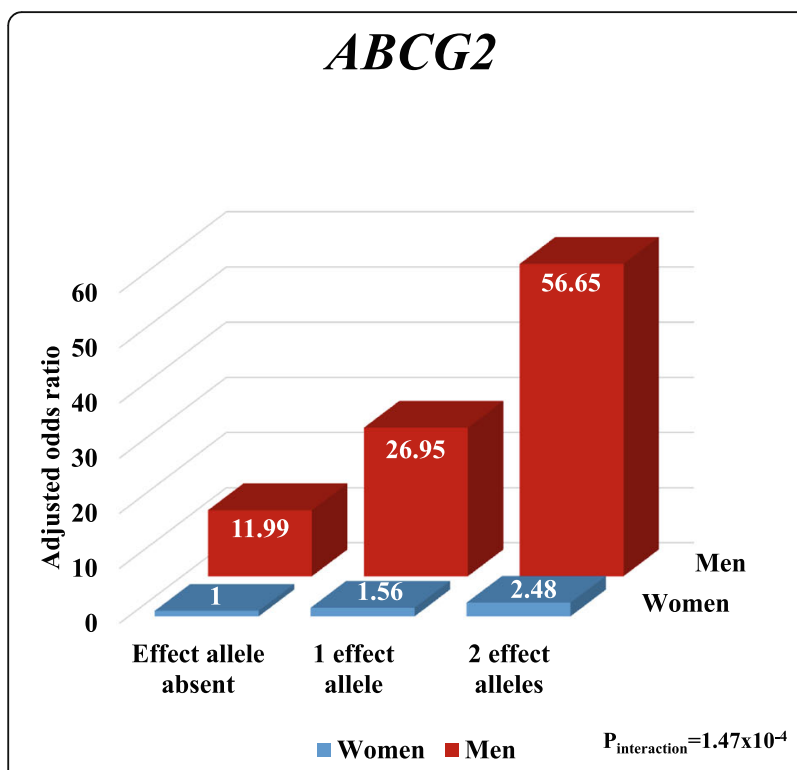

PDZK1

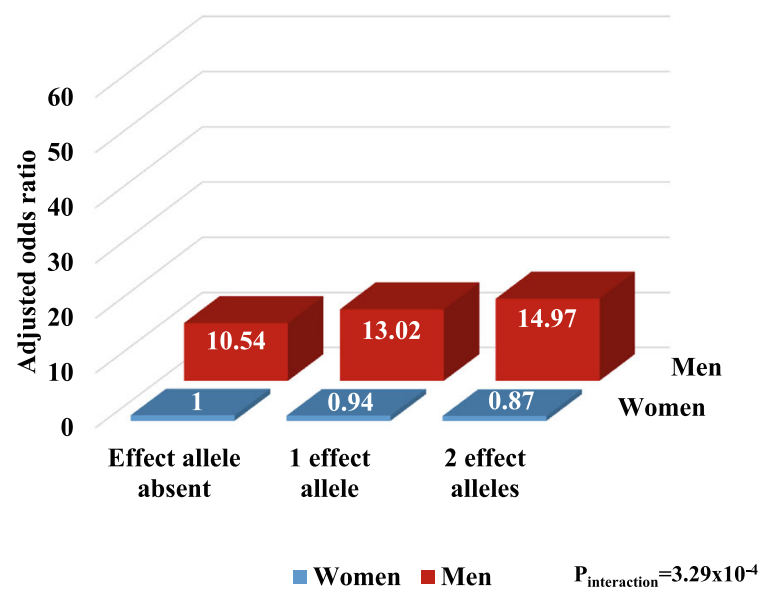

Fig. 3 Association and interaction between serum urate-associated genetic variants (for $A B C G 2$ and $P D Z K 1$ ) and sex for gout risk according to the number of effect alleles present. Data are adjusted for age, body mass index, renal failure, and diuretic use. Experiment-wide significance is defined as $P<0.0017$

populations of non-European ancestry. The age range for recruitment into the UK Biobank means that younger people with early onset gout, and older participants over the age of 70 years were not included in the analysis. Despite the large size of the UK Biobank, the number of women with gout in our analysis was low, which may have affected the power to detect small differences between groups. Co-morbidity and medication use data collected via the UK Biobank resource was through self-report. This method of data collection may not accurately represent the true prevalence of co-morbidities such as renal failure and medication use. However, this imprecision is likely to have applied systemically to all groups in the analysis. An assessment of sex-specific differences in serum urate would strengthen the findings of our study. However, serum urate measurements are not currently available in the UK Biobank database. Strengths of this study include the large sample size with consistent methods of data collection, and comprehensive assessment including patient interviews, hospitalisation records, and medical information.

\section{Conclusions}

In people of European ancestry, gene-sex interactions for gout risk exist for $A B C G 2$ and $P D Z K 1$, with the effect alleles exerting a greater influence on gout risk in men than in women. In contrast, other serum urate-associated variants, including $S L C 2 A 9$, do not demonstrate gene-sex interactions for gout risk.

\section{Additional files}

Additional file 1: Table S1. Genotype frequencies of 30 serum urateassociated single-nucleotide polymorphisms according to group overall and sex. Table S2. Frequencies and association analysis of 30 serum urateassociated single-nucleotide polymorphisms for gout in all patients. Table S3. Frequencies and association analysis of 30 serum urate-associated singlenucleotide polymorphisms for gout. Table S4. Association and interaction between serum urate-associated single nucleotide polymorphisms and sex for gout risk, excluding pre-menopausal women. Table S5. Association and interaction between serum urate-associated single nucleotide polymorphisms and sex for gout risk according to the number of effect alleles. (DOCX $62 \mathrm{~kb}$ )

Additional file 2: Figure S1. Association and interaction between serum urate-associated genetic variants (for $A B C G 2$ and PDZK1) and sex for gout risk according to effect allele presence, excluding pre-menopausal women. Data are adjusted for age, body mass index, renal failure, and diuretic use. Experiment-wide significance is defined as $P<0.0017$. (PPTX $44 \mathrm{~kb}$ )

\section{Abbreviations}

ABCG2: ATP-binding cassette subfamily G member 2; ARIC: Atherosclerosis risk in communities; Cl: Confidence interval; GCKR: Glucokinase regulator; GWAS: Genome-wide association study; MLXIPL: MAX-like protein X interacting protein-like; OR: Odds ratio; PAGE: Population architecture using genomics and epidemiology; PDZK1: PDZ domain containing 1; SD: Standard deviation; SLC17A1: Solute carrier family 17 member 1; SLC22A11: Solute carrier family 22 member 11; SLC2A9: Solute carrier family 2 member 9; SNP: Single nucleotide polymorphism

\section{Acknowledgements}

Not applicable.

\section{Funding}

This work was supported by the Health Research Council of New Zealand (grant number 14-527). This research has been conducted using the UK Biobank Resource under Application Number 12611.

\section{Availability of data and materials}

The data in this study are owned by a third party, UK Biobank (www.ukbiobank.ac.uk). Legal constrains do not permit public data sharing but it is open to all bona fide researchers worldwide. The data reported can therefore be directly accessed by applying through the 
UK Biobank Access Management System (www.ukbiobank.ac.uk/ register-apply).

\section{Authors' contributions}

RKN analysed and interpreted the data, and drafted the manuscript. ND, TRM, and LKS contributed to study design, data analysis, and data interpretation, and contributed to the manuscript draft. RT and MC obtained the dataset from the UK Biobank. GG contributed with the statistical analysis. All authors read and approved the final manuscript. All authors are accountable for all aspects of the work.

\section{Ethics approval and consent to participate}

UK Biobank obtained approval from the North West Multi-Centre Research Ethics Committee (11/NW/0382). Full written informed consent was obtained from all participants prior to the study.

\section{Consent for publication}

Not applicable.

\section{Competing interests}

TRM has received consulting fees or grants from Ardea Biosciences and AstraZeneca. ND has received consulting fees, speaker fees, or grants from AstraZeneca/Ironwood, Kowa, Horizon, Amgen, Abbvie, and Janssen. The remaining authors declare that they have no competing interests.

\section{Publisher's Note}

Springer Nature remains neutral with regard to jurisdictional claims in published maps and institutional affiliations.

\section{Author details}

${ }^{1}$ Department of Medicine, Faculty of Medical and Health Sciences, University of Auckland, 85 Park Road, Grafton, Auckland 1023, New Zealand. 2Department of Biochemistry, University of Otago, 710 Cumberland Street, Dunedin 9012, New Zealand. ${ }^{3}$ Department of Medicine, University of Otago, Christchurch, 2 Riccarton Avenue, Christchurch 8140, New Zealand.

Received: 15 August 2018 Accepted: 4 December 2018

Published online: 09 January 2019

\section{References}

1. Zhu Y, Pandya BJ, Choi HK. Prevalence of gout and hyperuricemia in the US general population: the National Health and Nutrition Examination Survey 2007-2008. Arthritis Rheum. 2011;63(10):3136-41.

2. Harrold LR, Yood RA, Mikuls TR, et al. Sex differences in gout epidemiology: evaluation and treatment. Ann Rheum Dis. 2006;65(10):1368-72.

3. Harrold LR, Etzel CJ, Gibofsky A, et al. Sex differences in gout characteristics: tailoring care for women and men. BMC Musculoskelet Disord. 2017;18(1):108

4. Akizuki S. A population study of hyperuricaemia and gout in Japan-analysis of sex, age and occupational differences in thirty-four thousand people living in Nagano Prefecture. Ryumachi. 1982;22(3):201-8.

5. Annemans L, Spaepen E, Gaskin M, et al. Gout in the UK and Germany: prevalence, comorbidities and management in general practice 2000-2005. Ann Rheum Dis. 2008;67(7):960-6.

6. Wu EQ, Patel PA, Mody RR, et al. Frequency, risk, and cost of gout-related episodes among the elderly: does serum uric acid level matter? J Rheumatol. 2009;36(5):1032-40.

7. Nath SD, Voruganti S, Arar NH, et al. Genome scan for determinants of serum uric acid variability. J Am Soc Nephrol. 2007;18(12):3156-63.

8. Wilk JB, Djousse L, Borecki l, et al. Segregation analysis of serum uric acid in the NHLBI family heart study. Hum Genet. 2000;106(3):355-9.

9. Yang Q, Guo CY, Cupples LA, et al. Genome-wide search for genes affecting serum uric acid levels: the Framingham Heart Study. Metabolism. 2005; 54(11):1435-41.

10. Kottgen A, Albrecht E, Teumer A, et al. Genome-wide association analyses identify 18 new loci associated with serum urate concentrations. Nat Genet. 2013:45(2):145-54

11. Doring A, Gieger C, Mehta D, et al. SLC2A9 influences uric acid concentrations with pronounced sex-specific effects. Nat Genet. 2008; 40(4):430-6.
12. Vitart V, Rudan I, Hayward C, et al. SLC2A9 is a newly identified urate transporter influencing serum urate concentration, urate excretion and gout. Nat Genet. 2008;40(4):437-42.

13. Kolz M, Johnson T, Sanna S, et al. Meta-analysis of 28,141 individuals identifies common variants within five new loci that influence uric acid concentrations. PLoS Genet. 2009;5(6):e1000504.

14. Yang QO, Kottgen A, Dehghan A, et al. Multiple genetic loci influence serum urate levels and their relationship with gout and cardiovascular disease risk factors. Circ Cardiovasc Gene. 2010;3(6):523-30.

15. Phipps-Green AJ, Merriman ME, Topless R, et al. Twenty-eight loci that influence serum urate levels: analysis of association with gout. Ann Rheum Dis. 2016;75(1):124-30

16. Dehghan A, Kottgen A, Yang Q, et al. Association of three genetic loci with uric acid concentration and risk of gout: a genome-wide association study. Lancet. 2008:372(9654):1953-61.

17. Topless RK, Flynn TJ, Cadzow M, et al. Association of SLC2A9 genotype with phenotypic variability of serum urate in pre-menopausal women. Front Genet. 2015;6:313

18. Cadzow M, Merriman TR, Dalbeth N. Performance of gout definitions for genetic epidemiological studies: analysis of UK Biobank. Arthritis Res Ther. 2017;19(1):181.

19. Zhang L, Spencer KL, Voruganti VS, et al. Association of functional polymorphism rs2231142 (Q141K) in the ABCG2 gene with serum uric acid and gout in 4 US populations: the PAGE Study. Am J Epidemiol. 2013;177(9):923-32

20. Phipps-Green AJ, Hollis-Moffatt JE, Dalbeth N, et al. A strong role for the ABCG2 gene in susceptibility to gout in New Zealand Pacific Island and Caucasian, but not Maori, case and control sample sets. Hum Mol Genet. 2010;19(24):4813-9.

21. Nicholls A, Snaith ML, Scott JT. Effect of oestrogen therapy on plasma and urinary levels of uric acid. Br Med J. 1973;1 (5851):449-51.

22. Adamopoulos D, Vlassopoulos C, Seitanides B, et al. The relationship of sex steroids to uric acid levels in plasma and urine. Acta Endocrinol. 1977:85(1):198-208.

23. Atallah AN, Guimaraes JA, Gebara M, et al. Progesterone increases glomerular filtration rate, urinary kallikrein excretion and uric acid clearance in normal women. Braz J Med Biol Res. 1988;21(1):71-4.

24. Sumino $H$, Ichikawa $S$, Kanda $T$, et al. Reduction of serum uric acid by hormone replacement therapy in postmenopausal women with hyperuricaemia. Lancet. 1999;354(9179):650.

25. Doyle LA, Yang W, Abruzzo LV, et al. A multidrug resistance transporter from human MCF-7 breast cancer cells. Proc Natl Acad Sci U S A. 1998; 95(26):15665-70

26. Imai $Y$, Ishikawa E, Asada S, et al. Estrogen-mediated post transcriptional down-regulation of breast cancer resistance protein/ABCG2. Cancer Res. 2005:65(2):596-604.

27. Hartz AM, Mahringer A, Miller DS, et al. 17-beta-estradiol: a powerful modulator of blood-brain barrier BCRP activity. J Cereb Blood Flow Metab. 2010:30(10):1742-55

28. Merino G, van Herwaarden AE, Wagenaar E, et al. Sex-dependent expression and activity of the ATP-binding cassette transporter breast cancer resistance protein (BCRP/ABCG2) in liver. Mol Pharmacol. 2005; 67(5):1765-71.

29. Anzai N, Miyazaki H, Noshiro R, et al. The multivalent PDZ domaincontaining protein PDZK1 regulates transport activity of renal urateanion exchanger URAT1 via its C terminus. J Biol Chem. 2004;279(44): 45942-50.

30. Miyazaki H, Anzai N, Ekaratanawong S, et al. Modulation of renal apical organic anion transporter 4 function by two PDZ domain-containing proteins. J Am Soc Nephrol. 2005;16(12):3498-506.

31. Kocher $\mathrm{O}$, Comella N, Tognazzi K, et al. Identification and partial characterization of PDZK1: a novel protein containing PDZ interaction domains. Lab Investig. 1998;78(1):117-25.

32. Ketharnathan S, Leask M, Boocock J, et al. A non-coding genetic variant maximally associated with serum urate levels is functionally linked to HNF4A-dependent PDZK1 expression. Hum Mol Genet. 2018;27(22): 3964-73.

33. Higashino T, Matsuo $H$, Sakiyama M, et al. Common variant of PDZ domain containing 1 (PDZK1) gene is associated with gout susceptibility: a replication study and meta-analysis in Japanese population. Drug Metab Pharmacok. 2016;31(6):464-6. 
34. Li M, Li Q, Li CG, et al. Genetic polymorphisms in the PDZK1 gene and susceptibility to gout in male Han Chinese: a case-control study. Int J Clin Exp Med. 2015;8(8):13911-8.

35. Zhou ZW, Cui LL, Han L, et al. Polymorphisms in GCKR, SLC17A1 and

SLC22A12 were associated with phenotype gout in Han Chinese males: a case-control study. BMC Med Genet. 2015;16:66.

Ready to submit your research? Choose BMC and benefit from:

- fast, convenient online submission

- thorough peer review by experienced researchers in your field

- rapid publication on acceptance

- support for research data, including large and complex data types

- gold Open Access which fosters wider collaboration and increased citations

- maximum visibility for your research: over $100 \mathrm{M}$ website views per year

At BMC, research is always in progress.

Learn more biomedcentral.com/submissions 